\section{Sistema de saúde universal e território: desafios de uma política regional para a Amazônia Legal}

\author{
Universal health systems and territory: challenges \\ for a regional policy in the Brazilian Legal Amazon
}

\author{
${ }^{1}$ Faculdade de Medicina, \\ Universidade de São Paulo, \\ São Paulo, Brasil. \\ 2 Escola Nacional de Saúde \\ Pública Sergio Arouca, \\ Fundação Oswaldo Cruz, \\ Rio de Janeiro, Brasil. \\ 3 Núcleo de Investigações \\ em Sistemas e Serviços de \\ Saúde, Instituto de Saúde de \\ São Paulo, São Paulo, Brasil. \\ Correspondência \\ A. L. d'A. Viana \\ Departamento de Medicina \\ Preventiva, Faculdade de \\ Medicina, Universidade de \\ São Paulo. \\ Av. Dr. Arnaldo 455, 20 andar, \\ sala 2225, São Paulo, SP \\ 01246-903, Brasil. \\ anaviana@usp.br
}

\begin{abstract}
This article presents the results of a study on Federal health policy in the Brazilian Legal Amazon (BLA) from 2003 to 2005, aimed at backing the development of regional health policies. The region has peculiar dynamics, an extensive border area, and adverse social indicators. The methodology included documental and financial analysis, participatory observation, interviews with heads of various Federal Ministries and State and Municipal health secretaries from the BLA; characterization of geographic situations in the BLA; and field studies in 15 municipalities. Institutional consolidation of health policy proved to be low in the Amazon during the study period, due to structural, institutional, and political difficulties. The identification of six geographic situations was useful for systematizing land use differences with repercussions on health, and which should be considered when implementing public policies. There is a certain gap between Federal actions and territorial dynamics, expressed as a mismatch between the current policy and its recognition by local administrators. In addition to establishing a regional policy for the Amazon, there is an evident need for differentiated policies within the region.
\end{abstract}

Regional Development; Health Policy; Border Areas

\author{
Ana Luiza d'Ávila Viana 1 \\ Cristiani Vieira Machado 2 \\ Tatiana Wargas de Faria Baptista 2 \\ Luciana Dias de Lima 2 \\ Maria Helena Magalhães de Mendonça ${ }^{2}$ \\ Luiza S. Heimann ${ }^{3}$ \\ Mariana Vercesi Albuquerque 1 \\ Fabiola Lana Iozzi 1 \\ Virna Carvalho David 1 \\ Pablo Ibañez 1 \\ Samuel Frederico 1
}

\section{Introdução}

A superação dos padrões de iniqüidade em que o sistema de saúde se insere é um dos desafios para a ampliação da proteção social no Brasil. As desigualdades sócio-econômicas e sanitárias, no país, têm forte expressão territorial, indicando a importância de políticas públicas de corte regional nas várias áreas, incluindo a saúde.

Este artigo apresenta os resultados de uma pesquisa que teve como objetivo analisar a política federal de saúde para a região da Amazônia Legal, no período de 2003 a 2005, sob condução do Ministério da Saúde brasileiro, e inserida em uma agenda mais ampla do Governo Federal. Tal região é marcada por uma dinâmica sócio-espacial peculiar e indicadores sociais desfavoráveis. Suas singularidades trazem enormes desafios em termos da integração nacional e da integração do Brasil com outros países, face à extensa área de fronteiras internacionais e à multiplicidade de interesses e organizações presentes na região.

A discussão empreendida neste artigo se orienta pelas seguintes questões: Por que o território importa na definição das políticas públicas? Quais são as possibilidades e dificuldades de construção de uma política de saúde para a Amazônia Legal? Como abordar a complexidade e diversidade das situações sócio-espaciais existentes na Amazônia Legal? Como desenvolver políticas regionais em uma estratégia nacional de enfrentamento da iniqüidade em saúde? 
Para isso, faz-se, inicialmente, um debate do marco teórico-conceitual que orientou a pesquisa. A seguir, apresentam-se a metodologia usada na investigação e seus principais resultados. À luz da experiência analisada, o artigo conclui com uma discussão dos desafios no desenvolvimento de políticas de caráter regional na saúde, em um contexto de acentuadas desigualdades sócio-espaciais.

\section{Marco teórico}

Globalização, território e políticas públicas

O processo de globalização fez emergir um mercado global, cuja regulação reflete a pressão das grandes empresas sobre o Estado. As fronteiras dos Estados-nação tornaram-se porosas ${ }^{1}$ para a ação de empresas mundiais, que utilizam o território como recurso e se instalam nos pontos mais lucrativos, exigindo a criação de sistemas técnicos (infra-estrutura, redes, energia) e normativos (incentivos fiscais, leis, relações trabalhistas). O aumento da regulação corporativa e das possibilidades de circulação de informações, pessoas, mercadorias e dinheiro introduzem novas formas de uso do território.

A seletividade espacial - caracterizada pela preparação de algumas regiões pelas empresas, com apoio do poder público, para ganhar efetividade na escala econômica mundial - cria uma hierarquia entre os lugares, que se diferenciam pela capacidade de oferecer rentabilidade aos investimentos, levando a uma desintegração competitiva 2 do território.

No Brasil, a competitividade, expressa nas disputas entre entes federados e entre empresas por mercados, tem gerado conflitos políticos, orçamentários e sociais $3,4,5$. As políticas públicas têm contribuído para a manutenção dessa dinâmica perversa 6 , pois a sua relativa subordinação à lógica das grandes empresas não permite superar a fragmentação e exclusão territorial. A busca da cidadania deveria sobrepor-se aos interesses corporativos e tornar-se o principal objetivo da regulação do território a ser alcançada por meio de políticas públicas, a partir de uma outra pactuação entre os agentes sociais (poder público, empresas e sociedade civil).

\section{Abordagens relativas ao território}

A partir da década de 1970, a Geografia Nova, proposta por Santos 7, define e passa a enfatizar o espaço geográfico como instância social. O autor propõe o conceito de território usado ${ }^{8}$, híbrido de materialidade e ação, de forma e conteúdo, de meio construído e movimento da sociedade, gerado pelos homens, instituições e empresas.

A saúde, vista pela ótica geográfica, expressa as condições de existência do ser humano no território. Nesse sentido, entender as desigualdades sócio-espaciais e suas conseqüências para o bem-estar social, que extrapola o setor saúde, é fundamental para debater-se saúde e proteção social no mundo contemporâneo 9 .

A interpretação da complexa realidade e das particularidades da Amazônia Legal implica refletir sobre os fatores originados pela racionalidade da globalização e sobre as formas de trabalho e vida na região. Diante da variedade de situações existentes e dos acelerados processos de mudança na dinâmica de uso dos territórios, alguns conceitos foram utilizados como fios condutores na pesquisa.

A idéia de situação geográfica, proposta por Silveira 10 (p. 115), está associada à noção de evento, entendido como "veículo de algumas possibilidades existentes no mundo, na formação sócio-espacial, na região, que se depositam, isto é, se geografizam no lugar". Um conjunto de eventos, expressos em materialidade, norma e ações, modifica o valor dos lugares, alterando, desse modo, a situação.

A situação geográfica como categoria de análise do território usado considera as heranças dos processos históricos e ajuda a compreender algumas direções que orientam as dinâmicas futuras dos lugares ${ }^{10}$. Assim, pode servir de apoio à formulação de políticas públicas.

\section{A Amazônia Legal no cenário nacional}

Na formação sócio-espacial brasileira, as divisões regionais foram produzidas, em geral, para servir à implantação de políticas estatais 11. Todavia, a variedade de critérios que subsidiam cada recorte, para satisfazer interesses estratégicos específicos, prejudica a efetividade dos objetivos das políticas públicas e acirra desigualdades sócio-espaciais.

A Amazônia Legal, que corresponde a $60 \%$ do território brasileiro, recebeu essa denominação em 1966, para a realização de políticas específicas. Entre 1965 e 1985, os projetos desenvolvimentistas introduziram novos usos para o território amazônico, com efeitos sociais e ambientais graves 12,13,14,15, e geraram uma dinâmica econômica que ainda influencia o desenvolvimento da região e sua integração com o país e o exterior.

A partir da década de 1980, no contexto de crise do Estado, diminui a ênfase do Governo Federal em projetos de infra-estrutura e sociais para a Amazônia Legal. Pressões nacionais e internacionais levam ao fortalecimento do movimento $\mathrm{am}$ - 
bientalista preservacionista 16 e à criação de programas de proteção ambiental, disseminando-se o conflito entre os projetos desenvolvimentistas e os de preservação, com retração dos primeiros. Contudo, esse movimento não resolveu a questão da desigualdade e a exclusão social, com fraca presença do Estado 16, pois tais projetos não conseguiram gerar transferência de renda para a população e, em muitos casos, ampliaram os conflitos fundiários.

A dinâmica territorial atual é marcada pela persistência do ciclo pecuária-desflorestamentomadeireira, conflitos sociais, grilagem de terras, extração ilegal da madeira e queimadas. A essas heranças se sobrepõe a implantação de uma agricultura capitalizada, principalmente de soja, destinada à exportação, e a prática de uma pecuária moderna de corte. Tal dinâmica, muitas vezes, tende a desapropriar populações, levando ao aumento das migrações intra-regionais e ampliação das áreas periféricas das cidades 8,12,16,17,18.

Além das atividades corporativas que ocupam diversas áreas e dos projetos ambientalistas que criam territórios de usos especiais, existem, na Amazônia Legal, outras dinâmicas territoriais, como: a área de fronteira internacional, que possui conflitos ligados a atividades ilícitas e imigrações ilegais; duas metrópoles, que atraem um grande contingente populacional e sofrem com o crescimento desordenado; os espaços opacos 18, de baixo dinamismo econômico, sem atrativos aos projetos corporativos.

\section{O SUS, a regionalização e a Amazônia Legal}

A regionalização se configura no marco legal do SUS 19,20, como uma estratégia para a organização das ações e serviços públicos de saúde, associada à descentralização e à hierarquização.

Na década de 1990, a diretriz de regionalização foi reafirmada nas Normas Operacionais do SUS, que regularam o processo de descentralização 21 . No entanto, a análise dessas normas mostra que a racionalidade sistêmica, entendida como incorporação de critérios relativos à organização da rede de ações e serviços com vistas à ampliação do acesso e economia de escala, só passa a ser fortemente presente na regulamentação federal ao final da década 22 . Assim, se houve no período avanços no âmbito da descentralização político-administrativa, propiciados pelo consenso de diferentes agendas de reforma em torno dessa diretriz 23 , o mesmo não se pode dizer da regionalização. Além disso, a concepção de regionalização preponderante no debate setorial tem se voltado para aspectos relativos à organização da rede de serviços no âmbito intra-estadual, não implicando, necessariamente, a incorporação de uma lógica territorial mais abrangente e a articulação com outras esferas da política pública.

Pode-se dizer que, na implantação do SUS, assim como na trajetória prévia da política de saúde, a dimensão territorial não tem sido fortemente incorporada à formulação de políticas de saúde. A proposição de políticas de corte macrorregional, comum nas políticas de desenvolvimento, infra-estrutura e meio ambiente, não é predominante na saúde, embora existam estratégias regionais em áreas específicas, como o controle de endemias desigualmente distribuídas no território. Cabe mencionar iniciativas esporádicas que se direcionaram para regiões com maiores carências, como o Plano de Saúde da Região Norte - Planorte (Ministério da Saúde/Fundação Nacional de Saúde; 1999), em geral, com dificuldades de implantação e resultados limitados 24 .

Considerando as características do federalismo brasileiro, a pouca tradição da política de saúde no enfrentamento da questão macrorregional, as limitações da regionalização na trajetória da descentralização em saúde e as peculiaridades da dinâmica da Amazônia Legal, pode-se dizer que a implantação de uma política de saúde diferenciada para essa região representaria um processo complexo e uma inovação importante no âmbito do SUS.

$\mathrm{Na}$ análise de uma política com tais atributos, é necessário considerar a institucionalidade da política que, a partir dos conceitos de pathdependence e increasing returns propostos por Pierson 25, pode ser definida como a sua incorporação efetiva à vida institucional, aferida por regras formais e informais, de forma que as possibilidades de sua interrupção sejam reduzidas e de continuidade sejam aumentadas, com perspectiva de desdobramentos progressivos. Na pesquisa, a institucionalidade da política de saúde para a Amazônia Legal representou uma variável-chave e valorizou-se a compreensão dos motivos que a influenciaram.

\section{Metodologia}

A delimitação do objeto de pesquisa - a política federal de saúde para a Amazônia Legal de 2003 a 2005 - e as questões inicialmente levantadas exigiram uma combinação de métodos de investigação, visando à avaliação do processo de construção da referida política e de seus desdobramentos no período estudado.

As estratégias metodológicas desenvolvidas foram agrupadas em duas vertentes: a análise do 
processo de formulação e implantação da política federal de saúde para a Amazônia e a caracterização de diferentes situações geográficas existentes na região.

$\mathrm{Na}$ primeira vertente, a institucionalidade foi definida como variável-síntese do processo de formulação e implantação da política de saúde para a Amazônia, aferida pelas seguintes dimensões:

- Características do processo de planejamento da política regional, considerando formalidade, continuidade e consistência do processo e natureza do plano;

- Abrangência e apropriação da lógica regional pelas áreas do Ministério, expressa nos tipos de ações propostas e implantadas;

- Coerência entre formulação, planejamento, financiamento e regulação da política em uma lógica regional;

- Base de sustentação da política, interna e externa, ao Ministério da Saúde;

- Produtos e desdobramentos da política.

Para esta análise, foram adotadas as seguintes estratégias metodológicas:

- Levantamento e análise documental, abrangendo: documentos do Governo Federal e do Ministério da Saúde, com destaque para os planos de governo globais e específicos para a Amazônia; portarias do Ministério da Saúde; documentos e atas das reuniões de instâncias colegiadas do SUS (Comissão Intergestores Tripartite), do Ministério (Colegiado da Secretaria Executiva, Fórum de Descentralização), e das instâncias criadas em função da política de saúde para a Amazônia (Grupo de Trabalho da Amazônia Legal, Núcleo de Acompanhamento, Integração e Desenvolvimento para a Amazônia Legal);

- Análise financeira dos dados do Fundo Nacional de Saúde de 2001 a 2005, comparando os recursos federais destinados para a Amazônia Legal com o conjunto do país;

- Observação participante em reuniões no Ministério da Saúde e em oficinas regionais;

- Entrevistas com atores envolvidos com a política de saúde para a Amazônia: dirigentes e técnicos das várias áreas do Ministério da Saúde; dirigentes de outros Ministérios do Governo Federal (Meio Ambiente, Integração Nacional, Cidades, Defesa e Casa Civil); secretários estaduais de saúde da Amazônia; gestores locais (secretários municipais de saúde, de planejamento, prefeitos) em 15 municípios selecionados; representantes de instituições de pesquisa da região.

Quanto ao estudo e análise de diferentes situações geográficas na Amazônia, recorreu-se a aportes teóricos da geografia, visando somar elementos à discussão sobre as políticas regionais em saúde. A caracterização de situações ge- ográficas surge na perspectiva de dar visibilidade à dinâmica territorial existente na Amazônia e iluminar as diversidades nos usos do território na região, possibilitando um olhar mais abrangente dos gestores e a busca de ações mais condizentes com cada realidade.

A caracterização das situações geográficas, neste estudo, resultou de revisão teórica, de análise de documentos do Governo Federal 26,27,28 e de informações sociais, econômico-financeiras e de saúde para os 761 municípios da Amazônia Legal, obtidas das bases de dados do Instituto Brasileiro de Geografia e Estatística (IBGE) e do Departamento de Informática do SUS (DATASUS). Tal caracterização considerou as variáveis: fluidez territorial, especialização produtiva dos lugares, normas de regulação, urbanização e (des)metropolização, mobilidade populacional e conflitos de interesses. A combinação dessas variáveis possibilitou a compreensão das diferentes dinâmicas de uso do território na Amazônia, configurando seis situações geográficas. A seleção dos municípios para o trabalho de campo procurou considerar os mais representativos de cada dinâmica territorial, de forma a contemplar as seis situações geográficas e os nove Estados da região.

O trabalho de campo consistiu na realização de entrevistas com autoridades municipais, com destaque para os prefeitos, secretários de saúde, de planejamento e de meio ambiente, com o objetivo de compreender o contexto local da saúde, em sua relação com outros aspectos da dinâmica municipal (economia, sociedade, cultura, entre outros).

\section{Resultados}

\section{A institucionalidade da política para a Amazônia Legal}

Entre 2003 e 2005, houve um movimento do Ministério da Saúde em construir uma política regional para a Amazônia Legal, desencadeado pelo projeto do Governo Lula, iniciado em 2003, que tinha o compromisso com a estruturação de uma política de desenvolvimento sustentável para a região e com a redução das desigualdades sociais no país. Observa-se, no período, um esforço da política de saúde para acompanhar a agenda de prioridades do Governo Federal, expressa em documentos e iniciativas do Ministério da Saúde 29,30,31, bem como a proposição de algumas estratégias inovadoras de políticas de saúde para a região.

No entanto, a análise realizada referente à variável-síntese institucionalidade da política re- 
velou uma fragilidade da política de saúde para a Amazônia Legal no período, conforme demonstrado pela discussão das categorias abaixo.

No que diz respeito ao processo de planejamento da política regional, a baixa institucionalidade se expressou nas oscilações na coordenação da política e no processo de planejamento. Apesar da criação de grupos de trabalho e de negociação voltados para a política em questão, a análise das atas e relatórios de reuniões dessas instâncias e as entrevistas revelaram uma alta rotatividade dos representantes das áreas e a baixa participação direta de atores com maior peso político.

A natureza do Plano de Saúde para a Amazônia Legal também sugeriu certa fragilidade do processo, visto que esse se configurou mais como uma planilha de acompanhamento com grande número de ações fragmentadas (organizadas em seis eixos correspondentes a várias áreas do Ministério) do que como um plano integrado de intervenção, demonstrando uma dificuldade de priorizar e coordenar ações 31. Em 2005, houve a substituição dessa planilha por uma agenda política com ênfase em cinco desafios estratégicos para a região, que, apesar de destacados nos debates sobre a política, nesse ano, não conseguiram ser implementados 32 .

A apropriação da lógica regional pelas áreas do Ministério, em geral, foi baixa, uma vez que a política nacional de saúde no período não foi desenhada preferencialmente em uma perspectiva macro ou mesorregional. As áreas do Ministério, em geral, seguiram a sua lógica tradicional de formulação de políticas para o conjunto do país. Praticamente não houve, no período, políticas especialmente desenhadas para a Amazônia Legal que deveriam ser predominantes no âmbito de uma política de corte regional. Na realidade, a análise dos tipos de ações propostas pelas diversas áreas para compor o "plano" mostrou o predomínio de três tipos de estratégias: (a) algumas políticas nacionais com discriminação positiva para a Amazônia Legal (estratégia especial de lançamento de editais de pesquisa, mudança no incentivo financeiro do Programa Saúde da Família - PSF, financiamento diferenciado das ações de controle de doenças epidêmicas e endêmicas); (b) políticas nacionais gerais, mas com grande potencial de repercussão na Amazônia (mudança no financiamento de hospitais de pequeno porte, saúde indígena, estratégia para a região de fronteiras); políticas nacionais gerais com orientação para priorização para a Amazônia (estratégia de apoio técnico aos Estados, capacitação e fixação de profissionais).

Talvez uma das evidências mais gritantes da baixa institucionalidade tenha sido a pouca correspondência, no período, entre uma proposta de política regional e os mecanismos para operacionalizá-la, particularmente a ausência de projetos integradores e de instrumentos de financiamento para viabilizá-los. Isso porque a coerência entre formulação da política, planejamento, financiamento e regulação em uma lógica regional é um aspecto fundamental para a consolidação de uma política desse tipo.

Também se observaram limitações no que diz respeito à base de sustentação da política no período, interna e externamente ao Ministério da Saúde. Internamente, a análise das entrevistas e de atas de instâncias colegiadas do SUS e do Ministério da Saúde demonstrou que a política de saúde para a Amazônia Legal não ocupou lugar central na agenda dos altos dirigentes do Ministério da Saúde no período (ministros e secretários) nem nos debates daquelas instâncias. A política foi sustentada por alguns dirigentes intermediários que se responsabilizaram diretamente pela sua condução e empreenderam esforços para a sua concretização, por motivos de identidade regional (origem ou experiência prévia na região) ou pela aposta na relevância dessa política.

Externamente, na relação com o Governo Federal, em que pese o esforço da Saúde para acompanhar as diretrizes gerais do Governo iniciado em 2003, não houve integração suficiente com outras áreas de governo nem linhas de financiamento específicas para viabilizar uma política de saúde específica para a Amazônia. A limitada operacionalização do Plano Amazônia Sustentável 26 (projeto mais amplo de governo destinado à região) prejudicou o desenvolvimento de políticas de saúde de caráter regional. A precariedade da base de sustentação da política no Governo Federal foi tanto uma expressão como uma causa da baixa institucionalidade da política de saúde para a região.

Chama ainda a atenção o baixo reconhecimento da política federal de saúde para a Amazônia Legal pelos secretários estaduais e municipais de saúde da região entrevistados na pesquisa. Entre os secretários estaduais, houve uma contundente identificação de problemas comuns, que atingiriam especialmente os estados da região em relação ao restante do país, sugerindo certo senso de identidade regional. Por outro lado, tais secretários reconheceram uma baixa capacidade de articulação entre si para a construção de uma política regional ou para pressionar o Governo Federal nesse sentido e se mostraram críticos à política federal em curso, em geral, negando a existência de uma política de saúde específica para a Amazônia. Os gestores locais também se posicionaram criticamente quanto à política federal, acusando o Ministério da Saúde de distanciamento em relação à realidade local e mos- 
trando relativo desconhecimento de estratégias federais em curso.

Outra expressão da baixa institucionalidade se relaciona aos tipos de produtos e desdobramentos da política. Vale dizer que o período estudado foi relativamente breve (três anos) para o alcance de efeitos substantivos, dado o caráter incipiente e inovador da política analisada, que torna pouco provável o registro de resultados em curto prazo. Ainda assim, procurou-se mapear os desdobramentos da política e seus efeitos no âmbito político, técnico-operacional e financeiro.

Identificaram-se três desdobramentos principais da política de saúde para a Amazônia Legal no período estudado:

- No âmbito gerencial, a conformação do Observatório de Saúde da Amazônia, uma estratégia especificamente voltada para a região;

- No âmbito da Ciência \& Tecnologia, o lançamento de editais de pesquisa para a região e o esforço de construção de um Acordo Multilateral de Cooperação Técnico-Científica em Saúde de instituições da Região Amazônica;

- No âmbito da assistência, mudanças relativas ao financiamento do PSF que discriminaram positivamente os municípios da Amazônia Legal.

O Observatório de Saúde da Amazônia Legal representou um avanço para a sistematização de informações sobre a região, com a integração dos dados da saúde com os relativos a dinâmicas territoriais, com o objetivo de melhorar a qualidade das informações e a possibilidade de sua utilização pelos gestores (http://portal.saude. gov.br/portal/amazonia/area.cfm/id_area=590, acessado em 22/Dez/2006). Tal iniciativa se desenvolveu por meio da articulação do Ministério da Saúde com outros órgãos federais, particularmente com o Sistema de Proteção à Amazônia. Apesar de conhecido pelas demais esferas de governo, a sua utilização efetiva pelos gestores da saúde ainda era baixa no momento da investigação.

As iniciativas no âmbito da Ciência \& Tecnologia - lançamento de editais de pesquisa específicos para a região - e o Acordo Multilateral de Cooperação Técnico-Científica em Saúde, firmado entre várias instituições regionais de pesquisa em saúde, com o apoio do Ministério da Saúde (http://www.portal.saude.gov.br/ portal/arquivos/pdf/Rel_Decit.pdf, acessado em 22/Dez/2006), constituem avanços no sentido de fortalecer uma área estratégica da política pública para o desenvolvimento regional 33 , em que a Amazônia Legal apresenta carências importantes. Embora menos visíveis para os secretários estaduais e municipais, tais estratégias foram amplamente reconhecidas e valorizadas pelos vários representantes de instituições de pesquisa da região entrevistados.

Dentre esses três produtos, pode-se dizer que a mudança relativa ao financiamento do PSF foi a que teve maior reconhecimento interno e dos gestores das outras esferas de governo, por se tratar de uma reivindicação antiga da região, que foi debatida em instâncias de negociação intergovernamental. Além de efeito político e da possibilidade efetiva de ampliação do programa, essa medida também teve repercussão positiva, embora limitada, na destinação de recursos de atenção básica para a região.

Contudo, a análise dos efeitos financeiros da política federal de saúde para a Amazônia Legal no período não pode considerar apenas um programa isoladamente, mas deve abranger o conjunto de recursos destinados ao SUS, que seguem lógicas de alocação distintas. A Figura 1 mostra que, comparando o período 2003-2005 com o período 2001-2002, as áreas em que o aumento na destinação de transferências federais para municípios da Amazônia foi superior ao do conjunto do país foram o PSF, a saúde bucal, o combate a doenças endêmicas e epidêmicas e o incentivo para saúde indígena. Os dois primeiros são programas prioritários da gestão ministerial iniciada em 2003, que, ao que parece, tiveram algum tipo de discriminação positiva na região. Já o controle de doenças endêmicas e epidêmicas e a saúde indígena são áreas em que a Região Amazônica apresenta maiores necessidades de recursos. Para outros tipos de transferência, entretanto, o aumento nacional foi superior ao observado para a Amazônia ou houve até redução das transferências, fazendo com que o incremento do total das transferências federais para municípios da região tenha sido igual ao do conjunto de municípios do país (aumento de $7,9 \%$ nos dois casos).

Considerando o conjunto de recursos federais - que compreende, além das transferências para municípios, as transferências para estados, pagamento direto a prestadores e convênios -, observa-se que os recursos federais per capita para a Amazônia Legal permaneceram, no período de 2001 a 2004, sempre abaixo do per capita nacional (Figura 2). Isso sugere que a política nacional para a Amazônia, a partir de 2003, não teve força suficiente para reduzir essa diferença no período analisado, apesar de algumas estratégias específicas terem buscado priorizar ou discriminar positivamente a região.

Nesse contexto, a discussão dos motivos que influenciaram a institucionalidade da política de saúde para a Amazônia é fundamental para a compreensão dos desafios de consolidação dessa política. A análise empreendida identificou 
Variação percentual (média 2003-2005/média 2001-2002) das transferências federais diretas para municípios por programas. Brasil e Amazônia Legal.

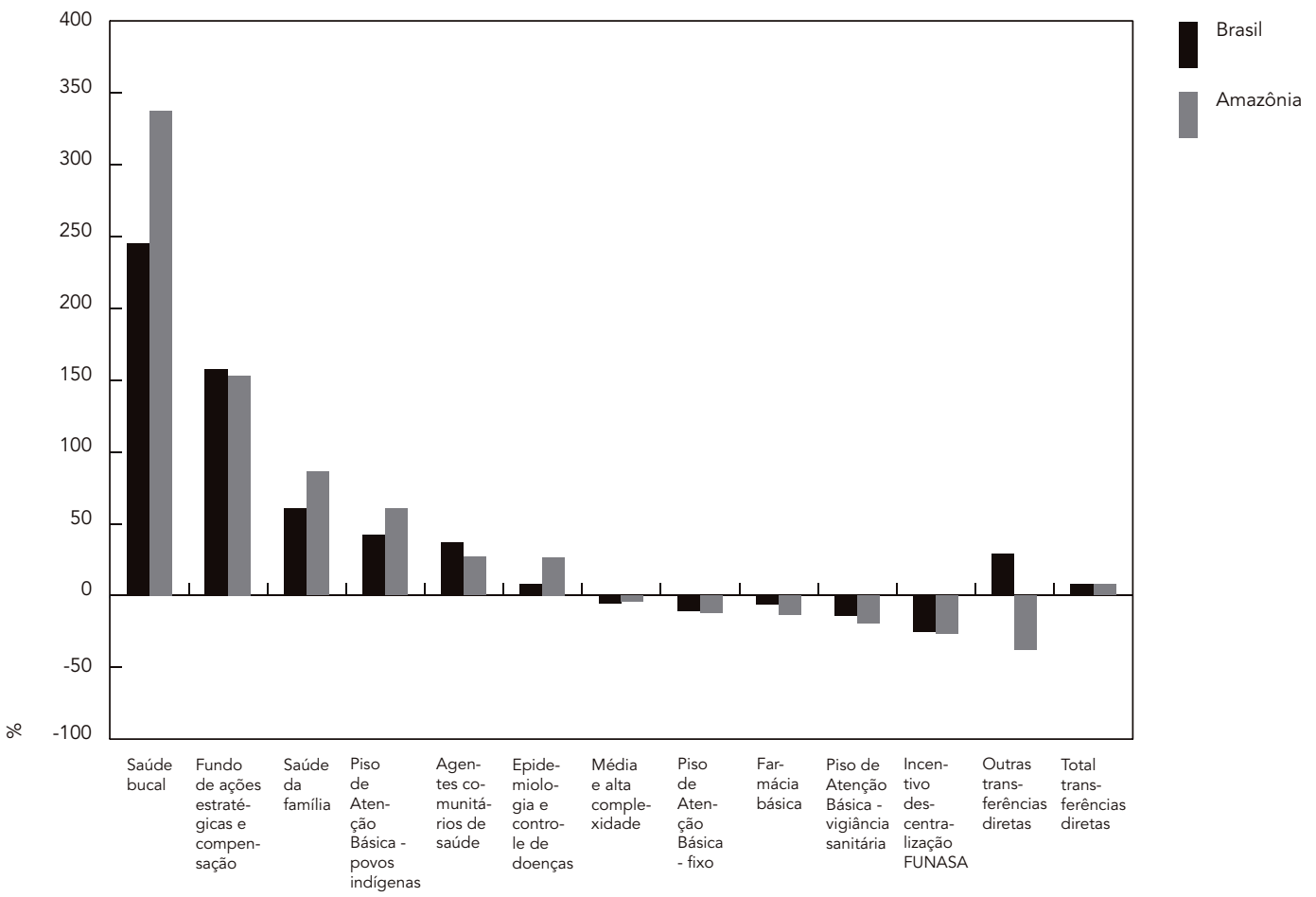

Fonte: elaboração a partir de dados do Sistema de Transferências Fundo a Fundo (SISFAF)/Fundo Nacional de Saúde/

Ministério da Saúde.

dificuldades de ordem estrutural, institucional e política.

As dificuldades estruturais são as que parecem apresentar maior força para explicar a baixa institucionalidade. Destacam-se, nesse âmbito, as características do federalismo brasileiro e do modelo de descentralização preponderante na esfera tributária e nas políticas públicas (em geral e na saúde), pouco favoráveis ao desenvolvimento de políticas regionais. Outras dificuldades estruturais se relacionam à limitada integração entre políticas públicas, que seria fundamental para o desenvolvimento regional; à complexidade da região, particularmente as grandes distâncias geográficas, dificuldades de acesso, isolamento e diversidade populacional, desigualdades sociais, multiplicidade e conflitos de interesses; e à baixa capacidade de articulação de atores regionais envolvidos com as políticas públicas.
Na realidade, as variáveis estruturais são importantes para explicar as dificuldades de concretização da política regional de governo consubstanciada no Plano Amazônia Sustentável 26, que repercutem na possibilidade de implantação de uma política regional específica na saúde. Um exemplo disso é que, no período analisado, houve um esforço do Governo Federal para reestruturar entidades administrativas de caráter regional e fortalecer fundos financeiros voltados para o desenvolvimento regional, que esbarrou na oposição dos governadores. As mesmas limitações se expressam na saúde, que não logra consolidar as instâncias de planejamento regional - a criação de estruturas administrativas com essa finalidade não é sequer cogitada no setor - nem obtém linhas de financiamento específicas.

Outro grupo de dificuldades é de ordem institucional, com destaque para a baixa tradição da área da saúde com políticas regionais e 


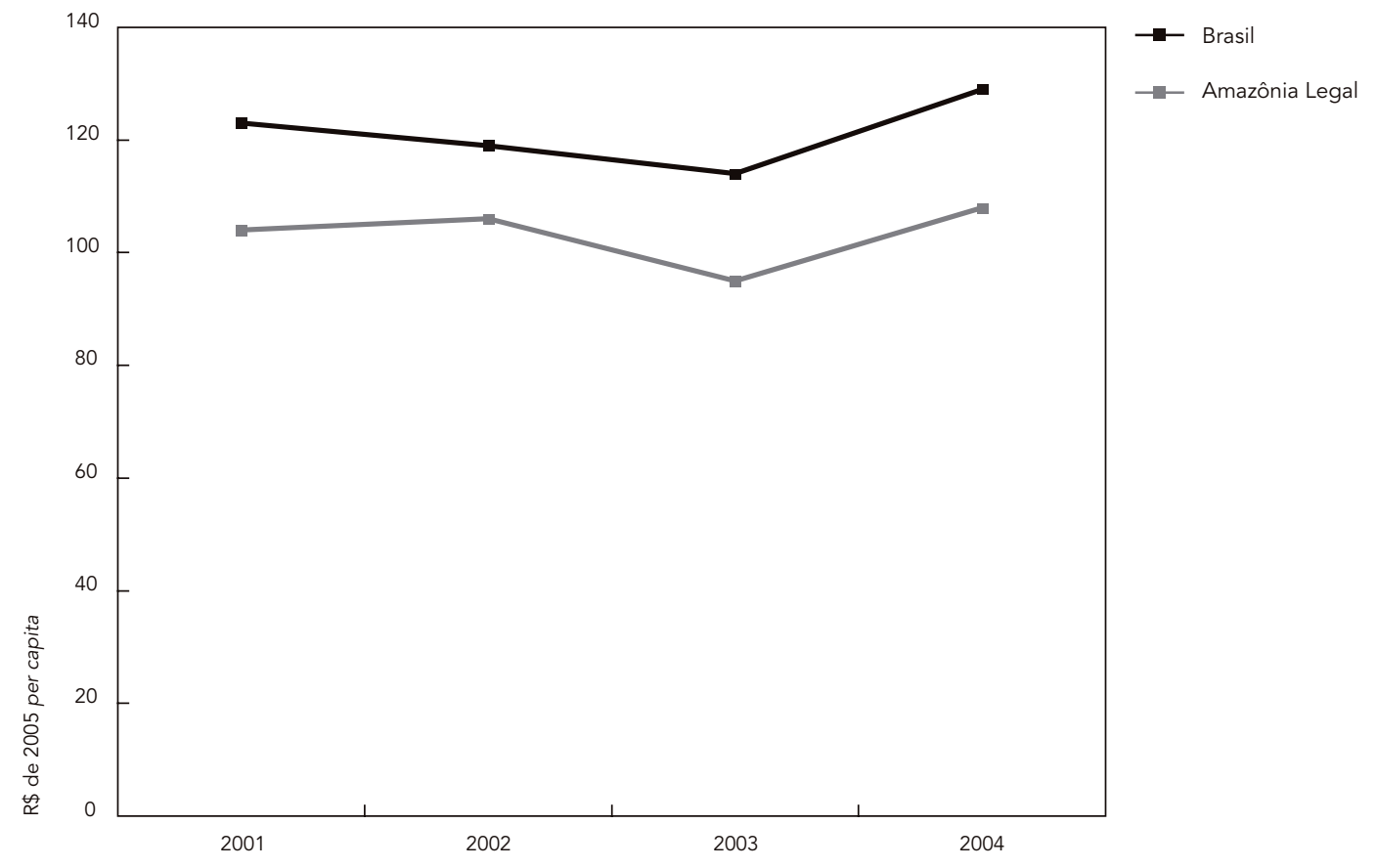

Fonte: elaboração a partir dos dados do Fundo Nacional de Saúde/Ministério da Saúde de 2001 a 2004, considerando o Sistema de Transferências Fundo a Fundo (SISFAF), os pagamentos realizados aos prestadores e os dados do Sistema de Gestão de Convênios (GESCON).

forma de atuação preponderante no Ministério da Saúde. No âmbito da formulação das políticas nacionais, convivem distintas lógicas, fruto da trajetória histórica das políticas: estruturação por programas voltados para problemas de saúde específicos, por grupos populacionais, por tipo de oferta (ambulatorial ou hospitalar), por nível de atenção (atenção básica, média e alta complexidade) e, mais recentemente, por porte populacional dos municípios. No entanto, a maior parte das políticas é proposta para o conjunto do país, com parca consideração das peculiaridades regionais. O debate sobre regionalização no Ministério da Saúde, nas últimas décadas, tem se dado em uma perspectiva tradicional, direcionada para a organização da rede de serviços no interior dos Estados. Portanto, de forma geral, a lógica regional não se mostra fortemente presente na formulação, planejamento, financiamento e regulação da política nacional de saúde.

Um último grupo de dificuldades se relaciona a variáveis políticas. Destacam-se, nesse sentido, as inflexões na conjuntura do Governo Federal, como a crise política, as mudanças na agenda governamental com deslocamento da prioridade, inicialmente conferida à Região Amazônica, e as alterações de quadros dirigentes do Ministério da Saúde, incluindo os responsáveis pela condução da política de saúde para a Amazônia Legal, levando a um contexto de instabilidade institucional. Outro motivo pode ter sido a baixa prioridade dessa política na agenda principal dos dirigentes do Ministério com maior poder decisório, visto que a pesquisa registrou uma distância entre o reconhecimento da relevância dessa política e a sua priorização efetiva por esses dirigentes. A própria estratégia de condução da política no âmbito do Ministério - a opção por uma lógica matricial e dialógica - e os conflitos internos podem ter trazido dificuldades adicionais à institucionalização da política em curto prazo.

No entanto, as dificuldades políticas não parecem ter sido as principais determinantes da baixa institucionalidade, visto que: (a) mes- 
mo no contexto de instabilidade institucional, outras políticas federais de saúde tiveram maior continuidade; (b) a agenda dos dirigentes da saúde não é elaborada somente a partir de suas preferências pessoais, mas é condicionada por fatores estruturais, institucionais e conjunturais, que restringem a sua governabilidade; (c) a negociação e os conflitos são inerentes ao processo de formulação de políticas públicas.

\section{Situações geográficas: estudos de caso}

A partir da análise das fragilidades do processo de construção e implantação da política federal de saúde para a Amazônia Legal, constatou-se a necessidade de buscar outros aportes teóricos e ampliar a pesquisa de campo. A caracterização das situações geográficas da Amazônia visou possibilitar a compreensão de como as dinâmicas territoriais podem influenciar a saúde e a identificação de elementos que pudessem oferecer uma base de suporte para o desenvolvimento de uma política de saúde com enfoque territorial. A Tabela 1 apresenta as principais características de cada situação geográfica e os municípios-caso estudados na pesquisa.

A partir das entrevistas nos municípios selecionados, foram valorizadas algumas variáveis para a análise das políticas públicas e de saúde, como: mobilidade populacional; cidades regionais; aspectos da descentralização; questões relacionadas à infra-estrutura; planos nacionais; problemas, organização e desafios do SUS.

Segue-se uma discussão dos resultados relativos a cada situação geográfica:

\section{- Usos corporativos do território}

Os usos corporativos do território representam uma situação geográfica expressiva na Amazônia Legal, caracterizada pela conformação de cidades funcionais à produção modernizada, que se tornam pólos regionais. O resultado da expansão dessa situação é o uso seletivo do território, acompanhado de geração de riqueza concentrada e pobreza difundida (crescimento das desigualdades), gerando um espaço corporativo e fragmentado.

Tais locais recebem diversos tipos de migrantes, concentrando investimentos e população. A existência de densidade técnica, científica e informacional favorece os serviços de saúde, no que diz respeito aos investimentos, infra-estrutura e atração de profissionais. Os municípios dessa situação, por terem um sistema de saúde mais consolidado, diversificado e privilegiado pelos recursos disponíveis, atraem população em busca de tratamento de saúde. Contudo, per- sistem problemas de insuficiência de recursos dos diversos tipos.

Apesar de seu poder político regional, enfrentam conflitos com a esfera estadual e com os outros municípios, especialmente na pactuação relativa aos fluxos de pacientes entre municípios e "tratamentos fora de domicílio".

Em síntese, a demanda por serviços geralmente é maior que a oferta e, embora disponham de maiores condições de arrecadação dos recursos, esses costumam ser insuficientes para atender às demandas crescentes de infra-estrutura e serviços básicos. Apesar de um maior desenvolvimento urbano, a falta de saneamento básico, comum a toda a Região Amazônica, também, nessa situação, apresenta-se como um sério problema de saúde. Com o aumento da população que busca melhores condições de vida, observa-se a lida com doenças conseqüentes do empobrecimento e precarização da habitação.

\section{- Fronteira de difusão dos usos corporativos do território}

Nessa situação, apesar da existência de elementos de modernização territorial, ainda não ocorreu a efetivação completa de um uso corporativo do território. Tais lugares compreendem atividades recentes que crescem com limitado planejamento e sem a presença de grandes corporações ou projetos federais. No entanto, essas localidades se privilegiam, ainda que indiretamente, de modernizações provenientes de construção e melhoramento das infra-estruturas ligadas à circulação.

Observa-se o aumento dos conflitos pela terra, visto que grileiros, aventureiros, sem-terra e mineradores buscam oportunidades, complicando a dicotomia entre usos conservacionistas e desenvolvimentistas. Isso é ressaltado pela existência de atividades que lidam diretamente com a exploração de minerais, madeira ou atividades agropecuárias com pouco conteúdo de tecnologia.

Já as cidades, apesar do aumento dos fluxos, reflexo das novas atividades, não se tornam funcionais a uma determinada produção, ou seja, não há uma sensível organização territorial que privilegie uma empresa. Os municípios atraem um grande contingente populacional que geralmente se aloja de forma precária nas periferias desprovidas de serviços básicos. Contudo, apresentam um precário desempenho no planejamento territorial urbano (habitação, saneamento básico, coleta de lixo) capaz de receber a população migrante, exacerbando problemas relativos à carência de infra-estrutura e tensões sociais. 
Tabela 1

Principais características e municípios selecionados por situação geográfica.

\begin{tabular}{lll}
\hline Situações geográficas & Caracterização & Municípios/Estado
\end{tabular}

Usos corporativos do território

Fronteira de difusão dos usos corporativos do território

Usos conservacionistas

\section{Áreas de fronteiras} internacionais
Difusão do meio técnico-científico-informacional ligado às atividades econômicas hegemônicas modernas

Investimentos voltados às infra-estruturas de fluidez para vantagens logísticas de exportações de commodities

Centro de atração populacional

Diversificação das atividades econômicas e complexização do sistema urbano

Cidades funcionais dentro da divisão internacional do trabalho

Especialização produtiva do território

Comércio e serviços mais desenvolvidos

Cidades médias que se tornaram centros regionais: nós de fluidez

Crescimento das desigualdades

Uso corporativo incompleto

Modernização recente de atividades produtivas e de infra-estruturas

Municípios inseridos em projetos federais de modernização

Lugares que estão recebendo grandes investimentos

Ampliação das modernizações e expansão da urbanização

Crescimento da atração populacional

Crescimento do poder político local

Áreas de intensificação de diferentes conflitos

Planejamento conservacionista de uso do território - demandas internacionais

Valor econômico da floresta - embate com outros projetos de desenvolvimento econômico Demarcação de áreas para a conservação e preservação da biodiversidade (áreas parciais

ou integralmente protegidas); projetos e investimentos de uso da biodiversidade Importância da regulação e fiscalização; justaposição de normas que regulam as áreas protegidas

Conflitos regionais em pequena e grande escala

População expropriada, não só da terra (preservada), mas de seu modo de existência tradicional

Grandes interesses internacionais (Ciência \& Tecnologia), cooperação internacional, participação de ONGs

Alguns lugares com maior organização política da sociedade civil, ligada aos movimentos sócio-ambientais

Fronteira Amazônica: mais extensa do país

Estratégias para o controle e a proteção: presença militar e caráter geopolítico

Muitas vezes, áreas de difícil acesso

Os municípios das áreas de fronteira internacional contam com normas específicas, além

das normas federais, estaduais e municipais; justaposição de normas

Área de fluxos internacionais: pessoas, capitais, mercadorias (lícitas e ilícitas)

Zonas de instabilidade e conflitos

Diversidade de redes e agentes: desafios à soberania do Estado

Diversidade de interações transfronteiriças: margem, zona-tampão, frente, capilar
Sinop/MT

Santarém/PA

Marabá/PA

Parauapebas/PA
Boa Vista/RR

Ariquemes/RO

Palmas/TO
Tefé/AM

Altamira/PA

continua 


\begin{tabular}{|c|c|c|}
\hline Situações geográficas & Caracterização & Municípios/Estado \\
\hline \multirow[t]{11}{*}{ Metropolização } & Abrigam as heranças do processo de urbanização brasileira & Belém/PA \\
\hline & Densidade: populacional, de infra-estruturas, serviços e indústrias & Manaus/AM \\
\hline & Ainda exercem atração populacional & \\
\hline & Sede de importantes instituições, como centros de pesquisa, ONGs, instituições financeiras & \\
\hline & e hospitais & \\
\hline & São os principais nós de fluidez na região & \\
\hline & Mercado interno mais desenvolvido, segmentado, diferenciado e hierarquizado & \\
\hline & Concentram maior especialização na divisão do trabalho & \\
\hline & Importância política frente aos novos projetos governamentais para a Amazônia Legal & \\
\hline & Intenso processo de precarização das condições de vida pelo aumento das desigualdades & \\
\hline & sócio-espaciais nas metrópoles & \\
\hline \multirow[t]{4}{*}{ Espaços opacos } & Menor densidade técnica e normativa & Sena Madureira/AC \\
\hline & Fluidez territorial rarefeita & Macapá/AP \\
\hline & Lugares à margem dos interesses da economia hegemônica moderna & Imperatriz/MA \\
\hline & Planos federais têm menor impacto & \\
\hline
\end{tabular}

As migrações relacionadas à urbanização acarretam demandas por serviços de saúde, que, muitas vezes, não acompanham esse crescimento. Os eventos de modernização não trazem, necessariamente, benefícios ao sistema de saúde. Entre os problemas de saúde da população, destacam-se ainda, as doenças infecciosas e parasitárias.

\section{- Usos conservacionistas}

Os usos conservacionistas incluem áreas protegidas por motivos ambientais e a demarcação de terras indígenas. Tais áreas trazem desafios à ação do Estado, por razões ambientais, econômicas e geopolíticas, evidenciando a necessidade de políticas públicas e de regulação adequadas às realidades amazônicas.

Nos municípios nessa situação geográfica, observa-se que novas demandas sociais surgem devido à expropriação da população habitante nas áreas de conservação. As normas de uso das áreas preservadas estabelecem condições nem sempre favoráveis à subsistência da população que, em grande parte, procura abrigo e trabalho no núcleo urbano mais próximo, colocando nova demanda aos serviços públicos. Ainda que muito tenha sido feito para que os projetos de preservação absorvam a população local, vários não estão de acordo com as novas regras.

Os municípios focos de movimentos ambientalistas, por terem alguma densidade técnica e normativa, costumam ser núcleos urbanos de referência na região e, às vezes, têm maior articulação política com a esfera estadual ou fede- ral nesse campo de interesse. No que concerne à descentralização, cabe ponderar que a institucionalização das reservas, em geral, não passa pelo âmbito municipal, predominando um processo "de cima para baixo".

Vale destacar que os projetos de uso conservacionista tendem a restringir outros projetos que poderiam significar maior arrecadação e geração de renda para os municípios. Além disso, a política ambiental, ao enfocar a biodiversidade, às vezes, não considera a vida urbana em sua complexidade, por exemplo, no que diz respeito às condições de saneamento básico ou à coleta de lixo.

Algumas dificuldades relativas ao sistema de saúde dos municípios onde há áreas de proteção ambiental se destacam. Por exemplo, os sistemas de informação disponíveis para a política ambientalista não favorecem, necessariamente, a melhoria das informações para a saúde. Outro exemplo é que, apesar de políticas de saúde diferenciadas para alguns grupos populacionais como a população indígena -, persistem problemas relativos ao acesso e à qualidade da atenção para esse e outros grupos. Ressalte-se que áreas extensas de preservação podem significar longas distâncias que trazem dificuldades de acesso aos serviços de saúde e de disponibilidade de profissionais capacitados para lidar com a população dessas áreas.

Uma característica desses municípios é que a proeminência de uma cultura de práticas tradicionais de saúde (relacionada à questão ambientalista) favorece uma abertura do SUS para a valorização e uso dessas práticas da Amazônia. 


\section{- Áreas de fronteiras internacionais}

As áreas de fronteira internacional da Amazônia Legal representam mais de $65 \%$ das fronteiras terrestres do território brasileiro. Nos municípios com área total ou parcialmente localizada na Faixa de Fronteira (150km de largura ao longo das fronteiras), incidem normas especiais que objetivam garantir a segurança do território nacional, que se somam às demais normas federais e estaduais existentes. Entretanto, a preocupação com a segurança nacional e o grande volume de normas não têm sido acompanhados de uma política pública sistemática que atenda às especificidades regionais, nem do ponto de vista econômico, nem da cidadania fronteiriça 33 .

A concentração de áreas protegidas ao longo da Faixa de Fronteira acrescenta outro conjunto de normas ambientais, que incidem sobre muitos municípios. Os Estados do Acre, Roraima e Amazonas, por exemplo, têm cerca de $70 \%$ de seus municípios sob legislação especial. Muitas áreas representam reservas indígenas, e algumas delas extrapolam o domínio territorial brasileiro 16 . Desse modo, as áreas que pertencem à faixa de fronteira conhecem restrições ao uso do território, devido à incidência de várias camadas normativas 3 .

Como a fronteira consiste em uma zona de contato entre territórios distintos, os municípios pertencentes a essa faixa acabam por apresentar um intenso fluxo material e imaterial, configurando lugares de marcante circulação de mercadorias, lícitas e ilícitas 33 .

No que concerne à saúde, os municípios da Faixa de Fronteira amazônica apresentam fortes elementos diferenciais. O primeiro é que alguns deles são de difícil acesso por meio terrestre, destacando a importância da colaboração das Forças Armadas no atendimento médico, odontológico e transporte de doentes.

O segundo é a grande mobilidade de população dos países vizinhos em busca de atendimento no sistema de saúde brasileiro. Esse fluxo não está contabilizado no cálculo dos recursos do SUS, acarretando conflitos no âmbito dos serviços e demandas dos municípios por mais recursos federais.

Um terceiro elemento é a presença de profissionais de saúde estrangeiros (legais e ilegais), principalmente de médicos, decorrente da dificuldade de fixação de profissionais brasileiros por deficiências de infra-estrutura e condições adequadas de trabalho.

Um quarto elemento é a necessidade da cooperação internacional para a prevenção e controle de doenças infecciosas (malária, tuberculose, AIDS), sendo fundamental fortalecer a cooperação entre países fronteiriços no nível local 34 .

Cabe ressaltar, por fim, que a localização de um município na faixa de fronteira não o isenta de apresentar diversos usos do território, visto que a fronteira internacional brasileira é bastante diversificada 33 . Nesse sentido, poderiam ser identificadas, nos municípios de fronteira, diferentes situações geográficas. Porém, sua localização fronteiriça acarreta fortes especificidades que devem ser consideradas na formulação das políticas de saúde.

\section{- Metropolização}

As duas metrópoles da Amazônia, Manaus e Belém, tornaram-se importantes pólos regionais, atraindo grande contingente populacional nos diferentes períodos de desenvolvimento na Amazônia.

Com as redes de transporte já constituídas, as metrópoles caminham para a difusão e concentração de redes modernas de telecomunicações, comandando a expansão das redes de fibra ótica e de informações do Sistema de Proteção da Amazônia. Esse aparato técnico, aliado à existência da Zona Franca de Manaus, contribui para a manutenção de seu poder de conexão com o território nacional e com o mercado externo, atraindo população e investimentos de empresas e instituições, o que aprofunda as desigualdades sócio-espaciais. Nessa situação, o poder político de Manaus e Belém é importante para as decisões de condução das políticas na Região Norte.

A concentração de densidades técnicas, científicas e populacionais favorece a diversificação e concentração dos serviços de saúde nessas metrópoles, que são centros de referência na Amazônia Legal para a produção científica, a formação de profissionais de saúde e o atendimento de média e alta complexidade. A raridade e precariedade desses serviços no restante da região geram uma enorme demanda de população proveniente do interior e de outros Estados, facilitada pelas redes de transporte que conectam Manaus e Belém com os demais municípios. Por esse motivo, evidencia-se uma tendência ao estrangulamento dos serviços de saúde.

As dificuldades de universalização e qualificação do acesso pela complexidade dos problemas urbanos e a precarização das condições de saúde nas áreas de ocupação recente e periferias são problemas significativos dessa situação geográfica. 


\section{- Espaços opacos}

Espaços opacos correspondem aos lugares que não apresentam densidade técnica, normativa e financeira necessária aos sistemas corporativos de produção e regulação do território, com baixa inserção no mercado nacional e internacional. A falta de redes técnicas de informação e a baixa geração de recursos financeiros constituem dificuldades para a formulação e implementação de políticas públicas.

Na Amazônia Legal, as situações de opacidade marcam municípios mais ou menos populosos, mais ou menos extensos territorialmente. A intensa transformação dessa região faz com que lugares tornem-se luminosos ou opacos numa velocidade assustadora, destacando a importância da mobilidade intra-regional na Amazônia.

Nos municípios opacos, a baixa concentração de atividades econômicas e arrecadação municipal acentuam a dependência dos recursos federais e estaduais para investimentos nos serviços de saúde. Observa-se carência de serviços, infraestrutura, programas e financiamento. Além da dificuldade de possuírem instituições formadoras, os municípios têm dificuldades de atrair e fixar profissionais. Nessa situação é freqüente o encaminhamento de pessoas para tratamento em outros municípios, inclusive de atenção básica, levando a altos gastos. Ademais, a grande precariedade das redes de transporte e comunicação dificulta a mobilidade da população para $o$ atendimento.

\section{Considerações finais}

Os resultados da análise da condução da política federal para a Amazônia Legal, no período estudado, mostraram que dificuldades estruturais, institucionais e políticas têm prejudicado o desenvolvimento de uma política regional e integrada de saúde para a Amazônia Legal.

A condução do Ministério da Saúde é ainda tímida frente aos desafios da construção de uma política regional. Um elemento a ser destacado é a escassa consideração das dinâmicas sócioespaciais na formulação das políticas setoriais. A trajetória da política de saúde demonstra fragilidades no enfrentamento da questão regional, revelando um padrão organizacional e de financiamento em que predominam estratégias homogêneas para todo o território nacional ou a proposição de recortes regionais com base somente na disponibilidade de serviços de saúde.

As marcantes desigualdades territoriais e sociais no Brasil, de difícil superação por meio de políticas setoriais isoladas, exigem a adoção de enfoques abrangentes sobre o território e o desenvolvimento de políticas públicas mais integradas. O fortalecimento da dimensão territorial no âmbito do SUS, uma política de grande expressão nacional, norteada pelos princípios de universalidade e igualdade, seria importante em um projeto nacional de enfrentamento das desigualdades, visando à cidadania.

As questões singulares que caracterizam a Amazônia apontam a necessidade de ações gerais e outras específicas, de forma a combinar uma política regional com meso e micro políticas, definição de programas específicos e apoio das esferas estaduais.

Muitos são os desafios a serem enfrentados no desenvolvimento de uma política regional de saúde para a Amazônia Legal: alto crescimento demográfico; expansão de pequenos e médios municípios; pouco desenvolvimento institucional no processo de descentralização na área social (limitada autonomia e baixa qualidade da gestão); limitado impacto das mudanças no financiamento federal da saúde na região; o caráter dos investimentos federais, geradores mais de governabilidade do que de eqüidade 24; e a persistente dificuldade de fixação de recursos humanos.

A caracterização das situações geográficas na Amazônia Legal possibilitou a identificação de múltiplas realidades, que influenciam a saúde $\mathrm{e}$ teriam implicações diferentes para processos de regionalização. Isso sugere não somente a necessidade de uma política regional para o conjunto da Amazônia, como de várias políticas regionais, dentro dessa região, que articulem estratégias para o desenvolvimento, a proteção social e a saúde.

O conceito de situação geográfica pode apontar um caminho para a formulação de políticas regionais em uma nova perspectiva, no sentido de reconhecer que o território usado, como instância social, interfere no funcionamento de políticas públicas. Para a saúde, a principal contribuição desse conceito é introduzir, no processo de planejamento da política, uma perspectiva dinâmica para o território, com ênfase nas diferenças e peculiaridades dos usos territoriais. Para o gestor federal, essa nova ótica significa transcender as regras verticais de organização do sistema nacional e aprofundar estratégias que compreendam maior integração com outras políticas públicas e demais esferas de governo no planejamento.

Cabe ponderar que o desenvolvimento de políticas em uma nova perspectiva territorial é necessariamente um processo de longo prazo. No caso da Amazônia, existe um histórico de iniciativas da saúde para região, em geral, com 
pouca integração com outras políticas, baixa institucionalidade e efeitos limitados. A pesquisa desenvolvida enfocou um período muito recente, dificultando conclusões sobre seus resultados e perspectivas, embora se considere um ponto positivo o esforço de um debate mais abrangente sobre a política regional para a Amazônia Legal no período estudado.

\section{Resumo}

O artigo apresenta os resultados de uma pesquisa sobre a política federal de saúde para a Amazônia Legal de 2003 a 2005, visando fornecer subsídios para o desenvolvimento de políticas regionais na saúde. Tal região é marcada por uma dinâmica peculiar, extensa área de fronteira e indicadores sociais desfavoráveis. A metodologia envolveu: análise documental e financeira, observação participante, entrevistas com dirigentes federais de vários ministérios, secretários estaduais e municipais de saúde da Amazônia; caracterização de situações geográficas na Amazônia e estudos de campo em 15 municípios. Observou-se uma baixa institucionalidade da política de saúde para a Amazônia, no periodo, por dificuldades estruturais, institucionais e políticas. A identificação de seis situações geográficas foi útil para a sistematização de diferenças nos usos do território que repercutem na saúde e devem ser considerados na condução de políticas públicas. Há certo distanciamento entre as ações federais e a dinâmica territorial, expressa no descolamento entre a politica em curso e seu reconhecimento pelos gestores locais. Além da construção de uma política regional para a Amazônia, fica evidente a necessidade de políticas diferenciadas dentro da região.

Desenvolvimento Regional; Política de Saúde; Áreas de Fronteira
Finalmente, refletir sobre uma política regional para a Amazônia Legal pode contribuir para fortalecer a perspectiva regional na condução da política nacional e para construir políticas de integração com os países vizinhos no âmbito da saúde.

\section{Colaboradores}

O marco teórico foi redigido por A. L. d'A. Viana, M. V. Albuquerque e V. C. David. A introdução, metodologia e resultados referentes à análise da institucionalidade da política foram redigidos por C. V. Machado, T. W. F. Baptista e L. D. Lima. A análise, sistematização e redação dos resultados referentes aos estudos de campo foram feitos por F. L. Iozzi, P. Ibañez e S. Frederico. A revisão geral e as considerações finais foram sistematizadas por M. H. M. Mendonça e L. S. Heimann.

\section{Agradecimentos}

Este projeto foi financiado por uma iniciativa conjunta do International Development Research Center/ Canadá e da Organização Pan-Americana da Saúde, com o apoio da AcademyHealth, como parte do programa de pesquisa Building and Bridging Health Services Research and Health Policy in the Americas: Extension of Social Protection in Health e co-financiado pelo Ministério da Saúde. 


\section{Referências}

1. Arroyo M. Território nacional e mercado externo: uma leitura do Brasil na virada do século XX [Tese de Doutorado]. São Paulo: Faculdade de Filosofia, Letras e Ciências Humanas, Universidade de São Paulo; 2001.

2. Araújo TB. Ensaios sobre o desenvolvimento brasileiro: heranças e urgências. Rio de Janeiro: Editora Revan; 2000.

3. Cataia MA. Território nacional e fronteiras internas: a fragmentação do território brasileiro [Tese de Doutorado]. São Paulo: Faculdade de Filosofia, Letras e Ciências Humanas, Universidade de São Paulo; 2001.

4. Ibañez P. Território e guerra fiscal: a perversidade dos incentivos territoriais [Dissertação de Mestrado]. São Paulo: Faculdade de Filosofia, Letras e Ciências Humanas, Universidade de São Paulo; 2006.

5. Silveira ML. Um país, uma região: fim de século e modernidade na Argentina [Tese de Doutorado]. São Paulo: Faculdade de Filosofia, Letras e Ciências Humanas, Universidade de São Paulo; 1997.

6. Santos M. Economia espacial: críticas e alternativas. São Paulo: Edusp, 1979.

7. Santos M. A natureza do espaço, técnica e tempo, razão e emoção. São Paulo: Editora Hucitec; 1996.

8. Santos M. O território e o saber local: algumas categorias de análise. Cadernos IPPUR 1999; 2:15-25

9. Rojas LI. Geografía y salud: temas y perspectivas en América Latina. Cad Saúde Pública 1998; 14:701-11.

10. Silveira ML. Uma situação geográfica: do método à metodologia. Revista Território 1999; (6):21-8.

11. Souza MA. Regionalização: o tema geográfico e político - o caso paulista. Boletim Paulista de Geografia 1976; (50):103-41.

12. Becker BK. Amazônia. São Paulo: Editora Ática; 1998.

13. Ab'Saber AN. Amazônia: do discurso à práxis. São Paulo: Edusp; 1996.

14. Gonçalves CWP. Amazônia, amazonias. São Paulo: Editora Contexto; 2001

15. Oliveira AU. Integrar para não entregar: políticas públicas e Amazônia. Campinas: Editora Papirus; 1988.

16. Becker BK. Amazônia: desenvolvimento e soberania. In: Rezende F, Tafner P, organizadores. Brasil: O Estado de uma nação. Rio de Janeiro: Instituto de Pesquisa Econômica e Aplicada; 2005. p. 199250.

17. Rojas LI, Toledo LM. Espaço \& doença: um olhar sobre o Amazonas. Rio de Janeiro: Editora Fiocruz; 1998.

18. Santos M., Silveira ML. O Brasil, território e sociedade no início do século XXI. Rio de Janeiro/São Paulo: Editora Record; 2001.

19. Brasil. Constituição da República Federativa do Brasil: promulgada em 5 de outubro de 1988. Brasília: Senado Federal; 1988.

20. Brasil. Lei no. 8.080, de 19 de setembro de 1990. Diário Oficial da República Federativa do Brasil 1990; 20 set.
21. Departamento de Apoio à Descentralização, Secretaria Executiva. Regionalização solidária e cooperativa. Brasília: Ministério da Saúde; 2006 (Série Pactos pela Saúde, 3).

22. Viana ALD`Á, Lima LD, Oliveira RG. Descentralização e federalismo: a política de saúde em novo contexto - lições do caso brasileiro. Ciênc Saúde Coletiva 2002; 7:493-507.

23. Levcovitz E, Lima LD, Machado CV. Política de saúde nos anos 90: relações intergovernamentais e o papel das Normas Operacionais Básicas (debate). Ciênc Saúde Coletiva 2001; 6:269-318.

24. Oliveira PTR. O Sistema Único de Saúde, descentralização e a desigualdade regional: um enfoque sobre a região da Amazônia Legal [Tese de Doutorado]. Rio de Janeiro: Escola Nacional de Saúde Pública, Fundação Oswaldo Cruz; 2005.

25. Pierson P. Increasing returns, path dependence and the study of politics. Am Polit Sci Rev 2000; 94:251-60.

26. Ministério da Integração Nacional/Ministério do Meio Ambiente. Plano da Amazônia sustentável. Brasília: Ministério da Integração Nacional/Ministério do Meio Ambiente; 2003.

27. Secretaria de Planejamento e Investimentos Estratégicos, Ministério do Planejamento, Orçamento e Gestão. Plano plurianual 2000-2003 - avança Brasil. Brasília: Ministério do Planejamento, Orçamento e Gestão; 2000.

28. Secretaria de Planejamento e Investimentos Estratégicos, Ministério do Planejamento, Orçamento e Gestão. Plano plurianual 2004-2007 - plano Brasil de Todos. Participação e Inclusão. Brasília: Ministério do Planejamento, Orçamento e Gestão; 2004.

29. Ministério da Saúde. Plano plurianual de governo para a saúde - PPA-Saúde 2004-2007. Brasília: Ministério da Saúde; 2004.

30. Ministério da Saúde. Portaria n ${ }^{\circ} .2 .607$ de 10 de dezembro de 2004. Aprova o Plano Nacional de Saúde - um pacto pela saúde no Brasil. Diário Oficial da União 2004; 13 dez.

31. Ministério da Saúde. Plano de qualificação da atenção à saúde na Amazônia Legal - Saúde Amazônia. Brasília: Ministério da Saúde; 2004.

32. Ministério da Saúde. Plano de qualificação da atenção à saúde na Amazônia Legal - Saúde Amazônia. Brasília: Ministério da Saúde; 2005.

33. Secretaria de Programas Regionais, Ministério da Integração Nacional. Programa de desenvolvimento da faixa de fronteira. Proposta de reestruturação. Brasília: Ministério da Integração Nacional; 2005.

34. Peiter PC. A geografia da saúde na faixa de fronteira continental do Brasil na passagem do milênio [Tese de Doutorado]. Rio de Janeiro: Instituto de Geografia, Universidade Federal do Rio de Janeiro; 2005.

Recebido em 19/Jun/2006

Versão final reapresentada em 27/Dez/2006

Aprovado em 03/Mai/2007 